\title{
ИСТОРИЯ ВОПРОСА О СУЩНОСТИ И НАПРАВЛЕНИЯ В ИЗУЧЕНИИ ВСТАВНЫХ КОНСТРУКЦИЙ В РУССКОМ ЯЗЫКЕ
}

Zohra Soudani, Université d'Alger(2), Algerie.

Pr. Terkmani Ouahiba, Université d'Alger(2), Algerie.

\section{Resume :}

\section{Вопрос о специфике вставных конструкциий,} семантической и грамматической связи с основным предложением в современном русском синтаксисе является не достаточно разработанным.В настоящее время вставные конструкции отличаются от вводных и рассматириваются как свободной синтаксической категорией.Однако, до сих пор, нет единого мнения о их связи с основным предложением и их роли в коммуникативном и семантическом планах.В данной статьи предпринята попытка разграничении этого лингвистического явления.

الملخص:

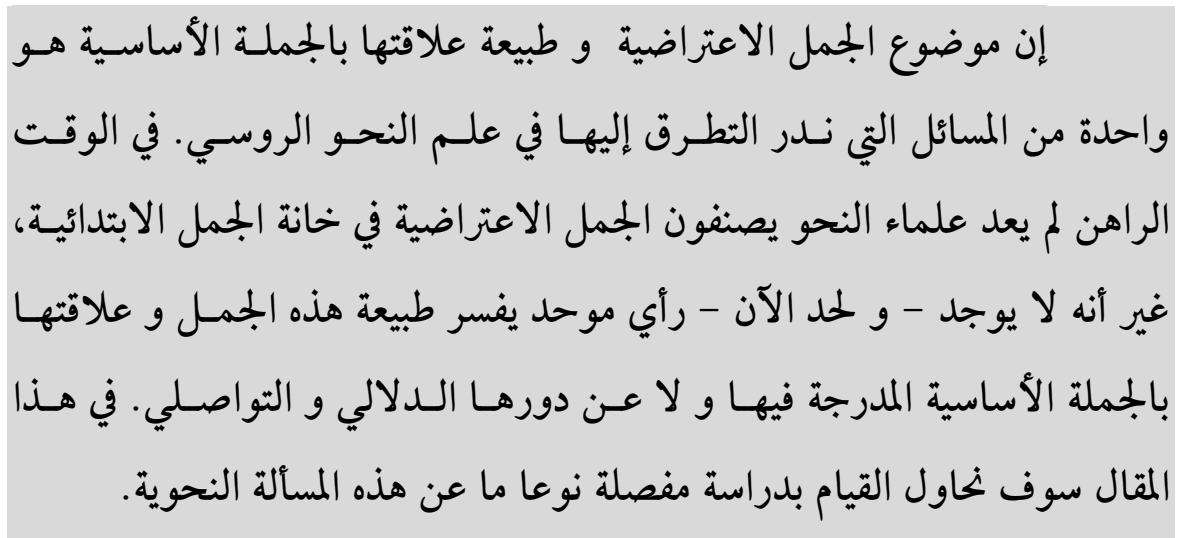


Одним из неразработанных вопросов синтаксиса русского языка является вопрос о специфике вставочных конструкций, о характере их смысловых и грамматических связей с тем преложением, в состав которого они входят. До сих пор в науке о языке остаются невыясненными принципами разграничения вводных и вставных конструкций и не обоснована сама необходимость этого разграничения.

На ранних этапах развития русской науки о языке вопрос о вставочных конструкциях специально не выделялся. Отдельные указания по этому поводу мы находим лишь в связи с изложением "правил о пользовании" "вместительным знаком" , т.е. скобками. Уже в "Российской грамматике" М. В. Ломоносова упоминание о вставочных конструкциях имеется в главе 4, озаглавленной "О знаках" , М.В. Ломоносов писал: " Вместитальное слово или целый разум в речь вмещает, без союза и порядочного сочинения: "Меня( кто бы подумал?) от тебя отлучают". [М. В. Ломоносов. 1855, с.52]

В трудах по грамматике А. А.Барсова. В. Тредиковского. M. Меморского пунктуационные правила относительно: "вместительного" знака, изложённые М. В. Ломоносовым, повторяются без особых изменений.

Сам термин "вставочная" конструкция был впервые введён Евграфом Филомафитским. Он исключает из числа "строчных" знаком препинания скобки и указывает: "Я бы даже 
не дал места среди знаком препинания и самым вместительным / ... / : они, заключая в себе так называемые предложения вложенные или вставочные, уже слишком много препинают или останавливают речь, - и плохим писателям дают как будто бы некоторое право быть темными и растянутными, хороший же писатель найдёт средств вложённое предложение поместить в свой речи и без вместительных".

Е. Филомафитский точко подметил характер прерывистой связи, устанавливаемой между вставкой и основным высказыванием, в то же время Филомафитский рассматривает наличие скобок в речи писателя как результат его стилистической беспомещности. Последнее положение, на наш взгляд, неправильно, т.к. вставки являются одним из преднамерённых приёмов, позволяющих автору выделить и подчеркнуть то, что по его мнению могло бы остаться незамеченным.

П.- Перевлисский в "Практической русской грамматике" правильно отметил, что вставные конструкции обладают особым назначением - выражать добавочное, попутное замечание, не являясь необходимой частью в составе основного высказывания, он характеризует вставные конструкции как синтаксически самостаятельные единицы. П. Перевлеский дал следующее определение вставным предложениям: "В составе речи нередко встречаются такие предложения, которые между 
членами предложени или периода встречаются без всякой грамматической связи: такие предложения называются вставочными.[П. Перевлесский. С.514].

Интересна мысль о вставочных конструкциях Н. Греча; в свой "Практической грамматике" он не выделяет вставные конструкции из числа вводных предложений. Под вводным же предложением Н. Гречь разумеет такое предложение, которое "не сочиняется с прочими и не подчиняется ясным, а просто вставляется в середине речи". В разделе "О вспомогательных знаках препинания" термин "вводные" Н.Гречь применил к вставным предложениям: "скобками, - замечает он, - отделяется предложение вводное, не состоящее с главным в граматической связи: Скажу тебе(пишет мой приятель, отставной капитан), что у нас все дешево. [Н. Греч.1827.С.358-362].

Н. Гречь правильно отметил наличие в языке вставных конструкций, правильно указал на их смысловые отношения с основным предложением. Но он не выделил вставные предложения как самостаятельный тип и смешал их с вводными, хотя между ними имеються существенные различия и в смысловых функциях и в структурно-грамматических свойствах.

В русской грамматике" (1831) А. Х. Востокова "вводные и вставные конструкции также не ограничиваются друг от друга. 
В учебных пособиях и диссертациях последнего времени в решении вопроса о вставных конструкциях нет единства. Большенство исследователей, следуя традиции, объединяют вводные и вставные конструкции в одну общую грамматическую категорию на основании прочно укоренившегося представления об абсолютной смысловой и грамматической изолированности вводных, а следовательно, и вставных конструкций от основной части предложения.

Некоторые лингвисты сближают вводные и вставные конструкции в функциональном отношении, утверждая, что как те, так и другие, одинакого используются в составе основного предложения для придания модального оттенка отдельному члену предложения или всему предложению в целом. Этого мнения придерживаются А. Г.Руднев, Л. Г. Хатиашвили и некоторые другие исследователи.

Другие авторы настаивают на необходимости разграничиния вводных и вставных конструкций, отличающихся друг от друга по своей функции и структурнограмматическим признакам (А. Б. Шапиро. А .И. Аникин).

Необходимость разграничения вводных и вставных конструкций впервые отметил А.Б. Шапиро в рецензии на работу С. И. Абакумова "Методика пунктуации. По мнению Шапиро, вставными являются "слова, группа слов, предложения или даже группа предложений, имеющих особую функцию - 
добавочного, ранее не предполагавшегося к включению в основную ткань предложения, замечания "[ А.Б.Шапиро. 1948.C.63]. Отсюда можно сделать вывод, что основным критерием в разграничении вводных и вставных конструкций, он считает особую функцию вставных конструкций: "добавочного, ранее не предполагавшегося ко включению в основную предложения, замечания."

А. И. Аникин в своей диссертации "вводные слова и словосочитания в русском языке "разграничивает вводные предложения и вставные. Вставные предложения в отличие от вводных не связаны с выражением модальности основного состава предложения, а содержат различные сведения, примечания, которые говорящий сообщает по ассоциации или в дополнении к основному предложению, в состав которого они вставляются, выделяются интонацией, а на письме - знаками припинания.

В некоторой степени на различия между этими конструкциями указывают сами названия "вводное" и "вставные". Семантика слова "вводное" уже говорит о том, что в состав основного предложения что-то не просто вставляется не имея к нему никакого отношения, а вводится,т.е. становится частью этого основного целого, так или иначе органически с ним связанного. 
. . . Поэта, быть может, на ступенях света ждала высокая ступень. / Пушкин А. С./

В отличие от вводных, вставные конструкции не всегда принадлежат говорящему: они могут заключать в себе замечание постороннего лица, комментарии автора, включённые в чужую речь и т.д.

Дневальный плавно, умудряясь бесшумно печатать шаг (ещё спят солдаты), двинулся навстречу сержанту.

Золушкин ? - секретарша встрепенулась, как от сна, - что же вы. асильевич/ не обошлось без легкой иронии) уехали, не оставив адреса?"

И. И. Щеболева в диссертации "вставочные конструкции в современном литературном языке " отмечает общие черты вводных и вставных конструкций и различия между ними.

\section{ОБЩИЕ ЧЕРТЫ:}

1/ И вводные и вставные конструкции могут быть связаны по смыслу как со всем содержаниям основного высказывания, так и с отдельным его компонентом.

2/ И вводные и вставные конструкции могут включаться в состав основного высказывания при помощи союзов и союзных слов. 
3/ Некоторые вставные конструкции так же, как и вводные, отличаются отсутствием формально - грамматической связи их с основным предложением, вследствие чего для тех и других известное значения приобретает местоположение их в составе основного высказывания. Кроме того, и вводные и вставные конструкции характеризуются определённой интонацией, которую они получают в устной речи.

Различия между вводными и вставными конструкциями сводятся к следующему:

Вставные и вводные конструкции отличаются друг от друга по своей функции в речи. Как известно, вводные слова, словосочетания и вводные предложения являются лексикограмматическим средством выражения модальности. Они выражают отношение высказываемого к действительности с точки зрения говорящего или различные реакции говорящего на действительность, в том числе и эмоциональную оценку ее.

Вставные конструкции не выполняют модальных функции, а употребляются для сообщения различного рода оговорок, ссылок, дополнительных замечаний, пояснений.

В отличие от вводных слов и вводных словосочетаний, характеризующихся ослаблением своего лексического значения, вставные слова полностью сохраняют свое лексическое значение. 
Вставные конструкции обладают особыми структурнограмматическими свойствами, отличающими их от вводных конструкций. Если вводные конструкции представляют собою доволно устойчивый круг слов и словосочетаний, а так же ограничённый круг структурных типов, то вставочные конструкции не связаны с определёнными лексикограмматическими средствами выражения. Наоборот, вставные конструкции характеризуются чрезвычайным разнообразиям структурных типов, ничем не отличающихся от невставочных конструкций.

"Академическая грамматика русского языка " 1954 года внесла известную ясность в трактовку синтаксических явлений, которые по традиции долгое время не различались. К "вставным" относит " слова и сочетания слов, синтаксически связанные с членами предложения, но представляющие собой разного рода попутные допольнительные примечания". "Вставные предложения - это . . . предложения, вносящие дополнительные, попутные замечания и интонационно обособленные . . . "[ Грамматика русского языка.1954, с.143]..

В настоящее время вставные конструкции выделены из состава вводных единиц в самостаятельную синтаксическую категорию. Однако до сих пор ещё нет единого мнения в понимании сущности вставных конструкций, соотношения и связи их с основным составом предложения, их роли в его 
камуникативной и смысловой организации. Всесторонее исследование вставочных конструкций в современном русском языке продолжает быть связанным с четким отграничением их от смежных с ними других синтаксических явлений, осложняющих простое предложение. 


\section{Список использованной литературы.}

1/ Аникин А. И. Лексико-семантические средства связей предложений. Учёнын записки МОПИ, № 332, М., 1970.

2/ Аникин А. И. Функции вставных конструкций в современном русском языке. Учёные записки МГПИ им. В. И. Ленина, № 259, 1967.

3/ Грамматика русского языка, т. 2. Синтаксис, ч. 2, изд. АН CCCP, M, 1960.

4/ Н. Греч. Практическая русская грамматика. Сиб., 1827.

5/ Кобрина Н.А. О вставных предложениях с союзным включением. Учёные записки ЛГПИ,1965, т. 22.

6/ Ковтунова И.И. Современный русский язык. Порядок слов и актуальное членение предложения. М. 1976.гл. 1, 4.7.

7/ Перевлесский. П. Практическая русская грамматика, ч.3. Начертания синтаксиса, изд.5, Сиб.

8/ Распопов И.П. Строение простого предложения в современном русском языке.М., 1970.

9/ Тихомиров В. Разграничение вводных и вставных конструкций в современном русском языке. "Русский язык в школе", 1963.

10/ Филомафитский. Е. О знаках препинания, вообще и в особенности для российской словесности, ч. 2, 1822. 
11/ Шеболева И.И. Структурные типы вставных конструкций в современном русском языке. Сб, ст."Вопросы синтаксиса русского языка" под ред. Г.В.Валимобой, ростов-на Дону, 1971. 